\title{
Vaginal Bleeding in the Nonpregnant Patient Received in Emergency at Yalgado Ouedraogo University Hospital of Ouagadougou, Burkina Faso
}

\author{
Yobi Alexis Sawadogo ${ }^{1,2 *}$, Boubakar Toure ${ }^{1,2}$, Issa Ouedraogo ${ }^{1,3}$, Sibraogo Kiemtore ${ }^{1,2}$, \\ Dantola Paul Kain 1,2, Adama Ouattara1,2, Hyacinthe Zamane ${ }^{1,2}$, Ali Ouedraogo', \\ Blandine Thieba ${ }^{1}$ \\ ${ }^{1}$ Unity of Training and Research in Health Sciences (UFR/SDS), University Ouaga I Professor Joseph KI-ZERBO, Ouagadougou, \\ Burkina Faso \\ ${ }^{2}$ Yalgado OUEDRAOGO Teaching Hospital of Ouagadougou, Ouagadougou, Burkina Faso \\ ${ }^{3}$ Teaching Hospital of Ouahigouya, Ouahigouya, Burkina Faso \\ Email: *sawalexis@yahoo.fr
}

How to cite this paper: Sawadogo, Y.A., Toure, B., Ouedraogo, I., Kiemtore, S., Kain, D.P., Ouattara, A., Zamane, H., Ouedraogo, A. and Thieba, B. (2018) Vaginal Bleeding in the Nonpregnant Patient Received in Emergency at Yalgado Ouedraogo University Hospital of Ouagadougou, Burkina Faso. Open Journal of Obstetrics and Gynecology, 8, 847-853.

https://doi.org/10.4236/ojog.2018.810088

Received: July 18, 2018

Accepted: August 21, 2018

Published: August 24, 2018

Copyright $\odot 2018$ by authors and Scientific Research Publishing Inc. This work is licensed under the Creative Commons Attribution International License (CC BY 4.0).

http://creativecommons.org/licenses/by/4.0/

\begin{abstract}
Objective: To describe the epidemiological, clinical and therapeutic aspects of cases of vaginal bleeding in the nonpregnant patient received in emergency at Yalgado OUEDRAOGO University Hospital. Materials and Methods: It was a retrospective and descriptive study that involved the clinical records of 326 patients collected from January 01, 2009 to December 31, 2013. Results: The average age of women was 47 years old with extremes at 12 and 82 years old. Women of childbearing age accounted for $61.6 \%$ and postmenopausal women $18.7 \% .70 .7 \%$ of women were pauciparous or nulliparous. Menorrhagia and pelvic pain were the main signs associated. This symptomatology required hospitalization in $85.2 \%$ of cases. The main aetiologies were uterine myomas $49.69 \%$, cervical cancer $23 \%$ and functional metrorrhagia $11.04 \%$. Progestin was the most used drug in $67.1 \%$ of cases. Total abdominal hysterectomy and abdominal myomectomy were the most commonly used surgical methods with $22.3 \%, 44.4 \%$ of cases. Eleven death cases were observed. Conclusion: Gynecological metrorrhagia is more common in women of childbearing age than in menopausal women. The main causes are fibroma, cervical cancer and functional metrorrhagia.
\end{abstract}

\section{Keywords}

Metrorrhagia, Gynecology, Aetiology, Treatment, Ouagadougou 


\section{Introduction}

Gynaecological metrorrhagia is any haemorrhage of genital origin, lesional or functional occurring outside menstruation and any pregnancy. They constitute a problem whose management is complex [1]. It is the frequent and distressing pathology that can endanger the vital prognosis of the woman. In fact, this abnormal vaginal bleeding, which disturbs the woman's daily life as much as possible, can also announce a serious underlying pathology such as cancer [1] [2] [3]. These are situations that have received relatively little attention in the literature [1]. The clinical condition of women most often results in frequent use of emergency care. According to Malcom G, knowledge about pathogenesis and guidelines for the management of this clinical problem was lacking, with relatively litthe basic or clinical research in the field [4]. Metrorrhagia is a real public health problem. It is observed at any age of woman's life. Their etiologies, prevalence and severity differ according to age of onset. Sometimes doctors fail to identify the causes of this condition throughout history and physical examination [1]. For Kazadi-Buanga in Senegal, genital haemorrhages out menstruation are a specific problem and common in gynecological consultation whose etiological factors deserve to be known to better adapt the treatment [5]. In Burkina Faso, studies on this condition are rare and the etiological approach is often difficult because of the inaccessibility and the unavailability of some necessary complementary examinations. This study is conducted with the aim of describing the epidemiological, clinical, therapeutic and evolutionary aspects in order to contribute to a better management of this pathology.

\section{Patients and Methods}

It was a cross-sectional study with retrospective data collection. The study covered the period from January 1, 2009 to December 31, 2013 (5 years) and took place in the Obstetrics and Gynecology Department of the Yalgado OUEDRAOGO University Hospital.

We included in this study all the women who had been received in emergency in the department for metrorrhagia without diagnosed pregnancy.

The sample size was estimated with the Schwartz formula $\mathrm{n}=(1.96)^{2} \mathrm{PQ} / \mathrm{i}^{2}$. The prevalence $\mathrm{P}=0.93$ was obtained by consulting the activity report of the University Hospital Yalgado OUEDRAOGO of the year 2013.

By accepting an alpha risk of $5 \%$ and a precision (i) of $95 \%$ the minimum sample size was 14 women. We included 326 women.

The data were collected using an individual survey form for each patient. Data sources included emergency consultation records, patient medical records and operating record books.

Ethically, the start of this study, we had an authorization to collect data from the Hospital Director and the Ethics Committee. During the collection, the anonymity and confidentiality of the information collected were respected. 


\section{Results}

We recorded 326 women who visited the emergency department between January 1, 2009 and December 31, 2013 for nonpregnant metrorrhagia. During this period, 38,165 women were admitted to the same service. Nonpregnant metrorrhagia represents $0.9 \%$ of admissions. The average age of the patients was 46 years with extremes of 12 and 81 years. The socio-demographic characteristics of women are listed in Table 1.

Clinically, metrorrhagia alone was the reason for consultation in $62.6 \%$. It was associated with menorrhagia in $17.8 \%$, postcoital metrorrhagia in $8.9 \%$, leucorrhea in $3.1 \%$ and pelvic pain in $7.7 \%$ of cases.

Vaginal speculum examination found a healthy cervix in $58.3 \%$ of patients, an ulcerated cervix in $24.5 \%$ of cases, a budding cervix in $11.3 \%$ of patients, an inflammatory cervix in $4.6 \%$ and others aspects in $1.2 \%$.

The vaginal examination noted that $54.6 \%(178 / 326)$ of the patients had a normal size uterus; $31.9 \%(104 / 326)$ had an enlarged uterus. In 13.5\% of women, size assessment could not be done.

Complementary examinations prescribed at admission were: pelvic ultrasound $72.4 \%$, cervical biopsy $16.9 \%$, hysterosalpingography $2.1 \%$, endometrial biopsy $0.6 \%$, vaginal sampling $1.2 \%$, Pap smear $3.1 \%$ and other tests $3.7 \%$. The hemogram requested from 285 patients had anemia (hemoglobin level less than 11 $\mathrm{g} / \mathrm{dl}$ ) in $82.80 \%$ of patients. The different etiologies found after assessment are recorded in Table 2.

Complementary examinations prescribed at admission were: pelvic ultrasound $72.4 \%$, cervical biopsy $16.9 \%$, hysterosalpingography $2.1 \%$, endometrial biopsy $0.6 \%$, vaginal sampling $1.2 \%$, Pap smear $3.1 \%$ and other tests $3.7 \%$. The hemogram requested from 285 patients revealed anemia (hemoglobin level less than $11 \mathrm{~g} / \mathrm{dl}$ ) in $82.80 \%$ of patients. The different etiologies found after assessment are recorded in Table 2.

Management was medical in 192 cases (58.7\%) and surgical in 134 cases (41.2\%). Initial management consisted of verification of the patient's stability. Emergency care was provided prior to specific care. Transfusion was required in 17 patients. The drugs used for medical treatment are listed in Table 3.

The different surgical procedures were myomectomy $62.7 \%$, total hysterectomy $24.6 \%$, cystectomy $6 \%$, polyp ablation $3.7 \%$ and curettage $2.1 \%$.

Of all patients received for metrorrhagia, 278 were hospitalized (85.3\%). The average hospital stay was 27 days with extremes of 3 and 51 days.

The clinical evolution of the patients was favorable in $93.6 \%$ authorizing their exit. Only $2.5 \%$ of patients were transferred to another department. Two patients were discharged against medical advice (0.6\%). The lethality was $3.4 \%$. The causes of death were cervical cancer (6 cases), post-myomectomy hemorrhagic shock ( 3 cases), 1 case of endometrial cancer and 1 case of ovarian cancer. 
Table 1. Socio-demographic characteristics of patients.

\begin{tabular}{|c|c|c|}
\hline Characteristics of patients & Number & Percentage \\
\hline \multicolumn{3}{|c|}{ Age } \\
\hline Under 20 years & 57 & 17.5 \\
\hline $20-44$ years & 200 & 61.3 \\
\hline $45-54$ years & 38 & 11.7 \\
\hline 55 - 64 years & 24 & 7.4 \\
\hline 65 years and over & 7 & 2.1 \\
\hline \multicolumn{3}{|c|}{ Socio-professional status } \\
\hline Housewives & 209 & 64.1 \\
\hline Informal sector workers & 37 & 11.3 \\
\hline Employees & 24 & 7.4 \\
\hline Students & 21 & 6.4 \\
\hline Shopkeepers & 12 & 3.7 \\
\hline Restated & 9 & 2.8 \\
\hline Unspecified & 14 & 4.3 \\
\hline \multicolumn{3}{|c|}{ Marital status } \\
\hline Married & 250 & 76.7 \\
\hline Celibatarian & 56 & 17.2 \\
\hline Concubine & 14 & 4.3 \\
\hline Divorcee-widow & 6 & 1.8 \\
\hline \multicolumn{3}{|c|}{ Number of pregnancies } \\
\hline Nulliparous & 81 & 24.8 \\
\hline Pauciparous & 155 & 47.5 \\
\hline Multiparous & 49 & 15 \\
\hline Grand multiparous & 41 & 12.6 \\
\hline
\end{tabular}

Table 2. Distribution of cases of metrorrhagia according to etiologies retained.

\begin{tabular}{ccc}
\hline Etiologies & Number & Percentage \\
\hline Uterine myomas & 162 & 49.7 \\
Cervical cancer & 75 & 23 \\
Functional metrorrhagia & 33 & 10.1 \\
Postcoital vaginal injury & 27 & 8.3 \\
Endometrial cancer & 06 & 1.8 \\
Cervical polyp & 06 & 1.8 \\
Chronic cervicitis & 05 & 1.5 \\
Ovarian Cyst & 05 & 1.5 \\
\hline
\end{tabular}




\section{Continued}

\begin{tabular}{ccc}
\hline Endometrial atrophy & 03 & 0.9 \\
Endometrial hyperplasia & 01 & 0.3 \\
endometriosis & 01 & 0.3 \\
IUD metrorrhagia & 01 & 0.3 \\
Coagulation disorder & 01 & 0.3 \\
Total & 326 & $100 \%$ \\
\hline
\end{tabular}

Table 3. Distribution of patients according to the drugs used.

\begin{tabular}{ccc}
\hline Drugs & Number & Percentage \\
\hline Progestins & 128 & 66.7 \\
Oestrogen plus progestin & 5 & 2.75 \\
Martial treatment & 40 & 20.2 \\
Analgesic & 22 & 11.5 \\
Anti-inflammatories & 51 & 26.5 \\
Haemostatic & 24 & 12.8 \\
Antibiotics & 93 & 48.8 \\
Others & 10 & 5.2 \\
\hline
\end{tabular}

\section{Discussion}

The relative frequency of metrorrhagia was $0.9 \%$. The frequency of vaginal bleeding in the nonpregnant patient varies considerably in the literature due to methodological differences in studies. Diarra AA in Mali had found a rate of 4.7\% [6]. According to Mary Gayle Sweet et al., abnormal vaginal bleeding occurs in $9 \%-14 \%$ of women between menarche and menopause [7].

The average age of women was 47 years old with extremes of 12 and 82 years. This is the same observation made in Mali by Diarra A [6]. His patients were between 14 and 87 years old with an average age of 42 years. The age group 19 to 45 years was the most prominent with a frequency of $61.3 \%$. This rate is similar to that of Diarra in Mali (59.60\% for the age group of 20 - 39 years) [6].

Vaginal bleeding in the nonpregnant patient can occur at any age. They are much more frequent in women in genital activity. In fact, pathologies such as fibroma and functional bleeding are common at this period of the woman's life [2].

Pauciparous were more represented with $47.5 \%$ followed by nulliparous $24.8 \%$. This is the same observation done by Diarra A [6]. This is understandable if we know that the main cause of metrorrhagia (the fibroid) is much more common in women who have had few children. Moreover, in our study, the fibroid is the first cause of metrorrhagia.

Identifying the cause of metrorrhagia is the most important element for management. 
It is known that clinical examination alone does not identify the cause of vaginal bleeding [1] [4]. Paraclinical examinations are therefore more than necessary for this purpose. This assessment must be requested according to the clinical orientation [8]. Nowadays, the consensus is made on the first-line examination in case of metrorrhagia: it is the vaginal ultrasound. Ultrasound allows a better appreciation of the uterus compared to the clinical examination [1]. This aspect has been confirmed by the results of this study. Indeed, the clinical examination had noted a uterine abnormality in 104 patients and the ultrasound revealed 162 abnormalities.

The majority of ultrasound scans that were performed in this study were abdominal. Currently all publications report the superiority of the vaginal ultrasound compared to the conventional abdominal route for the diagnosis of pelvic pathologies.

The causes of metrorrhagia during periods of genital activity are known, although sometimes the mechanism of bleeding remains enigmatic [4]. The causes are either organic or functional. The first cause of metrorrhagia in our study was uterine fibroid (49.7\%). This is the same observation done by several authors. For Telner E. D. et al., fibroids or polyps are the main causes of metrorrhagia [8]. For them $30 \%$ to $40 \%$ of women have fibroids. Diarra A in Mali noted that uterine fibroids ranked second in his study [6].

Cervical cancer, which is the second cause of metrorrhagia in our study (23\%), ranks 5th in the Diarra study in Mali [6]. This difference could be explained by the difference in level of hospitals (level 2 in Mali against level 3 in Burkina Faso).

The diagnosis of functional metrorrhagia was retained in $10 \%$ of women. It was the first cause in Mali according to Diarra A. For Malcolm, peripubertal bleeding accounted for $10.7 \%$ [4].

For specific management, progestin-only hormone therapy was the most prescribed medical treatment (67.1\%). This drug was used in the same proportions in Mali by Diarra. The literature is unanimous on the use of progestins for the medical treatment of vaginal bleeding in the nonpregnant patient [2] [4] [7]. In heavy bleeding, injectable estrogens are indicated as first-line. In our context this drug is not available.

Of all the patients admitted for metrorrhagia, none had presented a state of shock. Nevertheless, we noted cases of severe anemia that required blood transfusion in $8.9 \%$ of cases. The delay in consultation and the ineffectiveness of some medical treatments often result in severe anemia requiring transfusion.

Abdominal myomectomy was the most commonly used surgical method with $44.43 \%$. Total abdominal hysterectomy was second with $22.38 \%$. The young age of the patients and the desire to have a child explain the predominance of the conservative treatment in our series. In addition, nearly $3 / 4(72.3 \%)$ of the patients had given birth at most 3 times. In some countries, hysterectomy, which is the second treatment in our series, is the last resort for young women. Indeed, 
other treatments such as intracavitary tamponade, arterial embolization, endometrial resection that are recommended before hysterectomy, are not available at Yalgado Ouedraogo University Hospital.

In terms of prognosis, we recorded eleven deaths from all causes. The case fatality rate was $3.4 \%$. Cancer was the leading cause of death with $72.7 \%$. The other 3 deaths were observed in postoperative myomectomy by hemorrhagic shock in a context of blood scarcity.

Among the survivors, 305 patients had a favorable evolution, 08 patients were transferred for additional care in other services and 02 patients came out against medical advice.

\section{Conclusions}

Nonpregnant metrorrhagia is a major concern in the obstetrics and gynecology department. They are especially common among pauciparous women of childbearing age. Fibroids and cervical cancer were the main causes of this bleeding. Cancer cases are diagnosed at late, life-threatening stages. It is an affection that interests all ages and all professional categories.

A prospective study taking into account patients seen in outpatient clinics would make it possible to specify the extent and causes.

\section{Conflicts of Interest}

The authors declare no conflicts of interest regarding the publication of this paper.

\section{References}

[1] Ely, J.W., Kennedy, C.M., Clark, E.C. and Bowdler, N.C. (2006) Abnormal Uterine Bleeding: A Management Algorithm. The Journal of the American Board of Family Medicine, 19, 590-602. https://doi.org/10.3122/jabfm.19.6.590

[2] Borhart, J. (2013) Emergency Department Management of Vaginal Bleeding in the Nonpregnant Patient. Emergency Medicine Practice, 15, 1-20.

[3] Albers, J.R., Hull, S.K. and Wesley, R.M. (2004) Abnormal Uterine Bleeding. American Family Physician, 69, 1915-1926.

[4] Munro, M.G. (2013) Acute Uterine Bleeding Unrelated to Pregnancy: A Southern California Permanente Medical Group Practice Guideline. The Permanente Journal, 17, 43-56. https://doi.org/10.7812/TPP/13-018

[5] Kazadi Buanga, J. (2001) Metrorragies endo-uterines: Données étiologiques par l'histologie une série rétrospective de 214 curetages. Medecine d Afrique noire, 48 , 31-32.

[6] Diarra, A.A. (2008) Etude des métrorragies non gravidiques dans le centre de sante de référence de la commune I de Bamako. Thèse de Médecine, Université de Bamako, Bamako. http://www.keneya.net/fmpos/theses/2008/med/pdf/08M278.pdf

[7] Sweet, M.G., Schmidt-Dalton, T.A., Weiss, P.M. and Madsen, K.P. (2012) Evaluation and Management of Abnormal Uterine Bleeding in Premenopausal Women. American Family Physician, 85, 35-43.

[8] Telner, D.E. and Jakubovicz, D. (2007) Approach to Diagnosis and Management of Abnormal Uterine Bleeding. Canadian Family Physician, 53, 58-64. 